\title{
Research Paper:: The Relationship Between Psychiatric Problems and Eating Disorder Symptoms in Candidates for Bariatric Surgery
}

\author{
Elham Hojaji ${ }^{1}$ (D), Moslem Arian² (D), Seyedeh Fahimeh Shojaei ${ }^{3}$ (D), Saeed Safari ${ }^{4}$ (D), Behrooz Ghanbari ${ }^{*}$ (D)
}

1. Gastrointestinal and Liver Disease Research Center, Iran University of Medical Sciences, Tehran, Iran

2. Department of Counseling, University of Social Welfare and Rehabilitation Sciences, Tehran, Iran.

3. Firoozgar Clinical Research and Development Center, Iran University of Medical Sciences, Tehran, Iran.

4. Department of General Surgery, Iran University of Medical Sciences, Tehran, Iran.

\begin{tabular}{|l|l|l|l}
\hline $\begin{array}{c}\text { Use your device to scan } \\
\text { and read the article online }\end{array}$ & $\begin{array}{l}\text { Cttation: Hojaji, E, Arian, M, Shojaei, S. F., Safari, S, Ghanbari, S. (2021). The Relationship Between Psychiatric Problems } \\
\text { and Eating Disorder Symptoms in Candidates for Bariatric Surgery. Journal of Practice in Clinical Psychology, 9(3), 189-198. } \\
\text { https://doi.org/10.32598/jpcp.9.3.744.1 }\end{array}$ \\
dol'https://doi.org/10.32598/jpcp.9.3.744.1
\end{tabular}

\section{(c) (i) (8)}

Article info:

Received: 15 Nov 2020

Accepted: 21 Apr 2021

Available Online: 01 Jul 2021

Keywords:

Eating disorder, Obesity, bariatric surgery, Psychiatric disorders, Psychological distress

\section{ABSTRACT}

Objective: Obesity and overweight are global problems. They increase patient's morbidity and mortality and may cause severe medical conditions affecting physical, mental, and or social health. Bariatric surgery is a durable solution for treating morbid obesity. This study aimed to determine the associations between psychiatric problems and eating disorder symptoms in candidates for bariatric surgery.

Methods: In this cross-sectional study, 140 participants were selected from the patients who had already been referred to the obesity clinic in Firoozgar Hospital in Tehran, Iran, for bariatric surgery from April to June 2017. To collect study data, we used the eating disorder questionnaire for assessing eating disorders and the symptom checklist questionnaire for evaluating psychiatric problems.

Results: The results of the Chi-squared test showed a significant association $(\mathrm{P}<0.05)$ between eating disorder symptoms and psychiatric problems (phobia, anxiety, depression, obsessivecompulsive, psychoticism, hostility, paranoid ideation, and somatization). However, there was no significant correlation $(\mathrm{P}>0.05)$ between eating disorder symptoms and interpersonal sensitivity.

Conclusion: This study showed that eating disorders were significantly correlated with psychiatric problems.

\section{* Corresponding Author:}

Behrooz Ghanbari, PhD.

Address: Gastrointestinal and Liver Disease Research Center (GILDRC), Iran University of Medical Sciences, Tehran, Iran.

Tel: +98 (912) 4332180

E-mail: ghanbari.b@iums.ac.ir 


\section{Highlights}

- The necessity of identifying patients with psychiatric disorders before bariatric surgery.

- People who suffer from eating disorders are more likely to have psychological problems.

\section{Plain Language Summary}

Mental disorders such as eating disorders have a critical effect on individuals and society. Eating disorders are among complex medical and mental illnesses that can severely affect the patient's healthiness and his or her relationships. One of the most widely known complications of eating disorders is obesity. An eating disorder is often not diagnosed as a mental disorder. Much research including this article has shown that the mental aspect of eating disorders is more prevalent than we think. Also, various research shows that the prevalence of mental illnesses co-exists with eating disorders. Addressing both during treatment is very important for obesity surgery candidates and most of them struggle with various mental health problems. being aware of this, health care providers can create better conditions for people suffering from obesity.

\section{Introduction}

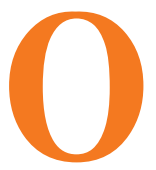

besity and overweight pose a global concern. According to a 2016 World Health Organization report, 39\% and $13 \%$ of adults were overweight and obese, respectively. Also, the prevalence of obesity was $21.7 \%$ in Iranian adults (Rahmani et al., 2015). The more obese the patients get, they will experience more physical, mental, and social problems. Various studies have been conducted on the relationships between psychological factors and obesity and overweight (Scott, McGee, Wells, \& Browne, 2008). These studies investigated a bilateral association between psychiatric disorders and obesity.

Patients with obesity and comorbid eating disorders are at risk of developing multiple medical and psychosocial complications (da Luz, Hay, Touyz, \& Sainsbury, 2018). Thus, it is claimed that people with eating disorders predominantly suffer from one or more anxiety disorders. Also, eating disorders can be positively related to emotional distress and depression (Moosavi \& Amini, 2017). People with eating disorders experience severe disturbances in their eating behaviors and related thoughts and emotions. People with eating disorders typically become preoccupied with food and their body weight (Health, 2011). The symptoms of eating disorders are factors that affect general health.

The prevalence of these symptoms has been increasing over the past few decades. They are classified into four main categories: shape concern, weight concern, eating concern, and restraint. These symptoms begin with mild states such as disturbance in the attitude towards eating, and become severe clinical conditions. So it is important to identify those who are at risk and the causes of these disorders (Pourghassem, Hamed, Seied, Kooshavar, \& Karami, 2010).

Bariatric surgery is a way to treat morbid obesity. By reducing body weight in the long term, this surgery can improve and reduce psychiatric and eating disorders (van Hout, Boekestein, Fortuin, Pelle, \& van Heck, 2006). Bariatric surgery candidates with eating disorders are at risk of psychiatric disorders (Lemstra \& Rogers, 2016). It has also been argued that surgical, non-surgical, and psychological factors play vital roles in long-term surgical outcomes.

Losing weight after surgery requires behavioral alterations and the ability of people to change their lifestyle permanently (Greenberg, Sogg, \& Perna, 2009). So, the preoperative psychiatric assessment is essential in deciding on the indication of obesity surgery (Mitchell et al., 2012). In a study to assess the prevalence of eating disorders among bariatric surgery patients, the results showed a high prevalence of severe binge eating (33.3\%) in this group. Also, severe binge eating was associated with grazing behavior and depression (Saunders, Johnson, \& Teschner, 1998).

A study in Iran showed that weight loss after bariatric surgery improved the physical component of quality of life. Still, this improvement did not affect the mental aspect of life, depression, and anxiety (Matini, Jolfaei, Pazouki, Pishgahroudsari, \& Ehtesham, 2014). In another study conducted by Duarte-Guerra et al. (2017), the rate of psychiatric disorders in these patients was $57.8 \%$. 
Research showed that surgically-treated morbidly obese patients with a psychiatric disease have a more unorganized eating pattern (with a predominance of binge eating and disinhibition) than the non-psychiatric obese group (Guisado, Vaz, López-Ibor, \& Rubio, 2001). Another study found that patients undergoing weight loss surgery showed binge eating disorders and disordered eating, such as episodes of binge eating, a sense of lack of control over eating, and inappropriate compensatory behaviors (Cella et al., 2019). Despite these studies, previous studies have not examined the association between symptoms of eating disorders and psychiatric disorders in these patients.

Given the presence of symptoms of eating disorders in obese patients, and the need to assess bariatric patients for eating disorders before surgery (Saunders et al., 1998), it seems necessary to examine the psychological factors and their relationship to eating disorders before obesity surgery. Also, assessing the severity of eating disorders and their relationships with psychological problems in obese and bariatric surgery patients can help the degree of preoperative intervention. Thus, this study aims to determine the link between psychological problems and eating disorder symptoms among candidates for bariatric surgery. Also, given the high incidence of obese patients for bariatric surgery, research such as this can help clinicians to diagnose and treat eating and psychological disorders before surgery because psychological, social, and behavioral factors may play an important role in postoperative outcomes.

\section{Materials and Methods}

In this cross-sectional study, participants were selected from the patients already been referred to the obesity clinic. The patients voluntarily enrolled in this study and signed the consent form. Finally, 140 obese patients that became candidates for bariatric surgery were selected and referred to the Obesity Clinic in Firoozgar Hospital, Tehran City, Iran, from April to June 2017. The patients were either grade 3 obesity (Body Mass Index [BMI] $\geq 40 \mathrm{~kg} / \mathrm{m}^{2}$ ) or grade 2 obesity (BMI $=35-40 \mathrm{~kg} / \mathrm{m}^{2}$, accompanied by diabetes, hypertension, or other related obesity diseases) and were considered for bariatric surgery. They were in an age range of 18-65 years (men and women). The patients were excluded if they were taking psychiatric or antidepressant drugs or having cognitive impairments and mental disorders (such as memory impairment) according to the clinical judgment of the psychiatrist using Mental Status Examination (MSE).
The height and weight of the patients were self-reported and completed by questionnaire, and BMI was calculated by dividing the weight $(\mathrm{kg})$ by the square of the height (m). Also, we used two questionnaires to determine the relationship between psychiatric problems and eating disorder symptoms in bariatric patients.

\section{The Eating Disorder Questionnaire (EDE-Q 6.0)}

The Eating Disorder Questionnaire (EDE-Q) was used to assess eating disorder symptoms. This tool was based on the full-length semi-structured interview-based Eating Disorder Examination (EDE), which has been considered the gold standard in assessing the specific psychopathology of eating-disordered behavior (Baceviciene, Balciuniene, Jankauskiene, 2020). This questionnaire was designed to evaluate the cognitive and behavioral characteristics of eating disorders in the patient's past 28 days. The eating disorder symptoms questionnaire comprised 28 items with four subscales of restraint, shape concern, weight concern, and eating concern. To obtain a particular subscale score, the ratings for the relevant items were added together, and the sum was divided by the total number of items forming the subscale. Then, an overall score for the four subscales was obtained, and the resulting total was divided by the number of the subscales. If the whole test score was equal or more than 4, disorder symptoms were indicated (Mahmoodi, Moloodi, \& Ghaderi, 2016).

The original version of the EDE-Q 6.0 has been extensively studied, and its good psychometric properties have been globally demonstrated in Portuguese, Spanish, Japanese, Persian, and other nations (Baceviciene et al., 2020). The Persian version of this questionnaire has also been examined by Moludi et al., who obtained the acceptable reliability and validity of the questionnaire with an internal consistency of 0.91 . They examined the internal consistency through calculating the Cronbach $\alpha$ value. The internal consistency values for the subscales were as follows: restraint, 0.78; eating concern, 0.73 ; shape concern, 0.81; and weight concern, 0.69 (Mahmoodi et al., 2016).

\section{The Symptom Checklist (SCL)-90-R}

The Symptom Checklist (SCL)-90-R is a psychological symptom assessment questionnaire. It is a psychiatric self-assessment checklist of 90 questions, rated on a 5-point Likert scale from $0=$ "not at all" to 4="strongly". The SCL-90-R questionnaire covers nine primary symptoms: somatization, obsessive-compulsive disorder, interpersonal sensitivity, depression, anxiety, anger-hos- 
tility, phobic anxiety, paranoid ideation, and psychoticrelated questions. For taking the SCL-90 test, the person needs first to read a phrase and mark that phrase, considering the given description at the beginning of the test. For those who are illiterate, the phrase should be read for them by an interviewer, which would help them to tick off the correct answer. In the end, all marked phrases in each scale are separately added and then divided by the number of phrases in each scale to find the mean value of that scale. The interpretation of the obtained mean value should be made with caution. The mean value greater than 1 indicates psychiatric disorder, greater than 2 indicates severe depression, and greater than 3 indicates psychosis. In a study on bariatric surgery candidates, the internal consistency coefficients for the 9 subscales of the SCL-90-R questionnaire were 0.76-0.90 (Ransom, Ashton, Windover, Heinberg, \& Diseases, 2010).

\section{Study procedures}

Initially, the code of ethics (IR.IUMS.REC. 1396.31076 No.) was received by the Iran University of Medical Science (IUMS). Then, the demographic characteristics of the patients were recorded by referring to the Obesity Clinic of Firozgar Hospital. After considering the physical fitness of the patients and the possibility of verbal communication, the purpose of the study was explained to them.

The study data were collected by conducting the clinical interview by a psychiatrist and completing questionnaires of EDE-Q 6.0 and SCL-90. Also, a personal information checklist collected the age, sex, marital status, education, family history of obesity, obesity in childhood, alcohol addiction, and smoking habit of the candidates.

The inclusion criteria were the patients' consent to enter the study without insistence or encouragement. Also, they could leave the survey whenever they wished. Before the study, they signed the data confidentiality form. The candidates were excluded from this study if they took psychiatric or antidepressant drugs or had cognitive impairments and mental disorders (such as memory impairment).

For the statistical analysis, we used SPSS v. 22. Normal Q-Q and detrended normal Q-Q plots were used to determine the normality of the data. Descriptive statistics were used for assessing personal information and eating disorder subscales. The Chi-square test was used for determining the relationship between eating disorder symptoms and psychological problems. Also, we used $\mathrm{R}$ software (v3.6) for drawing charts (for assessing the relationship between the total score of eating disorder symptoms and psychological issues).
A P-value less than 0.05 was considered significant. We used the following Equation to calculate the sample size:

$$
N=\frac{\left(z_{1-\alpha / 2}+z_{1-\beta}\right)^{2 *}\left(p_{1} q_{1}+p_{0} q_{0}\right)}{\left(p_{1}-p_{0}\right)^{2}}
$$

Considering alpha and beta values as 0.05 , the number of samples is found to be 140 (Papelbaum et al., 2005).

\section{Results}

The Mean \pm SD age of the candidates was $38.42 \pm 10.82$ years, within the range of $18-65$ years. The rest of the participants' demographic information is presented in Table 1. Also, the mean and standard deviation of the dimensions of eating disorder symptoms are present in Table 2. People who usually experience eating disorder symptoms tend to be more involved with psychological problems. Moreover, the Chi-square test showed that patients with eating disorder symptoms compared to those without these symptoms had a higher percentage of phobia (34.3\% vs $4.8 \%, \mathrm{P}<0.001$ ), anxiety disorder (34.3\% vs $13.3 \%, \mathrm{P}=0.006)$, depression disorder $(42.9 \%$ vs $18.1 \%, \mathrm{P}=0.003)$, obsessive-compulsive $(42.9 \%$ vs $21 \%, \mathrm{P}=0.011)$, psychoticism $(28.6 \%$ vs $5.7 \% \mathrm{P}=0.001)$, somatization ( $45.7 \%$ vs $21.9 \%, \mathrm{P}=0.007)$, hostility $(40 \%$ vs $19 \%, \mathrm{P}=0.012)$, and paranoid ideation $(45.7 \%$ vs $21.9 \%, \mathrm{P}=0.007$ ) (Table 3).

There were no significant differences between the two groups in reports of interpersonal sensitivity (40\% vs $23.8 \%, \mathrm{P}=0.064)$. The chart results showed that people with psychiatric disorders had higher eating disorder scores than healthy people. The chart results showed that with increasing incidence of psychiatric disorders, the eating disorder score also increased (Figure 1).

\section{Discussion}

This study aimed to evaluate the relationship between eating disorder symptoms and the psychiatric symptoms assessed by the SCL-90 questionnaire in obese patients candidates for bariatric surgery. The results show a significant difference $(\mathrm{P}<0.05)$ in 8 of the SCL-90 subscales (except for the interpersonal sensitivity subscale, where there was no significant difference).

The study results showed a significant relationship between eating disorder symptoms and somatization symptoms $(\mathrm{P}<0.05)$. About $45.7 \%$ of patients with eating disorder symptoms had somatization symptoms. A few studies have already demonstrated a relationship between eating disorder symptoms and somatization (Papelbaum, Moreira, do Nascimento Gaya, Preissler, \& Coutinh, 
Table 1. Brief summary of patients' characteristics

\begin{tabular}{|c|c|c|}
\hline \multicolumn{2}{|c|}{ Variables } & Mean $\pm S D /$ No.(\%) \\
\hline \multicolumn{2}{|c|}{ Height (cm) } & $164.56 \pm 9.5$ \\
\hline \multicolumn{2}{|c|}{ Weight (kg) } & $126.92 \pm 24.56$ \\
\hline \multicolumn{2}{|c|}{$\mathrm{BMI}\left(\mathrm{kg} / \mathrm{m}^{2}\right)$} & $46.61 \pm 7.22$ \\
\hline \multicolumn{2}{|c|}{ Age (y) } & $38.42 \pm 10.82$ \\
\hline \multirow[t]{2}{*}{ Education } & Under diploma & \\
\hline & Higher than diploma & $34(24.3)$ \\
\hline \multirow{2}{*}{ Marital Status } & Single & $49(35)$ \\
\hline & Married & $91(65)$ \\
\hline \multirow{2}{*}{ Family history of obesity } & No & 25(17.9) \\
\hline & Yes & $115(82.1)$ \\
\hline \multirow{2}{*}{ Obesity in childhood } & No & $63(45)$ \\
\hline & Yes & $77(55)$ \\
\hline \multirow{2}{*}{ Smoking } & No & $85(60.7)$ \\
\hline & Yes & $55(39.3)$ \\
\hline \multirow{2}{*}{ Alcohol addiction } & No & $117(83.6)$ \\
\hline & Yes & $23(16.4)$ \\
\hline
\end{tabular}

2010). Also, in a study on somatization factors, Papelbaum M. (2010) showed a significant relationship between body mass index and the SCL-90 psychosocial factor subscale. These patients had passive and dependent personality traits and exhibited symptoms of somatization (Lykouras, 2008). The possibility of a significant association between somatization and eating disorder symptoms may be attributed to the physical ailments that obese people suffer. These diseases can also impair one's mental state.

Moreover, the results of the present study showed a significant relationship (42.7\%) between eating disorder symptoms and obsessive-compulsive symptoms $(\mathrm{P}<0.05)$. Since eating disorders were first defined, they have been comorbid with symptoms of obsessive-compulsive disorder, and they have been positively correlated with it (Mohammadzadeh \& Vahedi, 2016).

Obsessive-Compulsive Disorder (OCD) is considered a risk factor for developing ED (Eating Disorder). The prevalence of OCD in patients with eating disorders is estimated at $2 \%-48 \%$. Some descriptive studies suggest that $50 \%-100 \%$ of patients with ED exhibit obsessive or compulsive characteristics. However, research in recent years has shown lower prevalence.

Obsessive and compulsive features in ED are different from those found in OCD and are more focused on food, weight, and shape. The compulsion seen in OCD is distinct from the compulsion in ED. Some of these behaviors include repetitive disturbing thoughts about food and weight in the ED and performing forced actions with repetition in OCD. However, the literature suggests a reciprocal relationship between ED and OCD (Tyagi et al., 2015). To explain the relationship between obsessive-compulsive disorder and eating disorder symptoms, we can argue that as patients gain weight, they are more concerned about their body image and appearance, leading to obsessive-compulsive thoughts.

Another finding of this study was a significant relationship (42.9\%) between eating disorder symptoms and depression symptoms $(\mathrm{P}<0.05)$. The most common psychiatric disorder accompanied by eating disorder was depression in $65 \%$ of cases (Saleem, Sattar, Zafar, \& Ismail, 2014). Research conducted on women aged 
Table 2. Mean $\pm S D$ of the total score and the subscales of eating disorder symptoms

\begin{tabular}{cc}
\hline Variables & Mean \pm SD \\
\hline Total eating disorder score & $3.27 \pm 1.10$ \\
Restraint & $1.34 \pm 1.52$ \\
Weight concern & $4.25 \pm 1.37$ \\
Shape concern & $4.81 \pm 1.23$ \\
Eating concern & $2.45 \pm 1.64$ \\
\hline & \\
\hline
\end{tabular}

13-34 years to determine the prevalence of alexithymia and depression in anorexia nervosa and its relationship with clinical variables showed that the prevalence of alexithymia and depression in patients with anorexia nervosa who had an eating disorder was $62.5 \%$ (Torres et al., 2011). When people are depressed or experience psychotic disorders, they may show symptoms of eating disorders due to lack of hope in life and the presence of metabolic diseases, respectively.

Also, we found a significant relationship $(28.6 \%)$ between eating disorder symptoms and psychoticism symptoms $(\mathrm{P}<0.05)$. In a study on personality characteristics and body weight, a significant relationship between psychotic personality characteristics and patients' weight was reported (Aragona, Petta, \& Balbi, 2015). Also, Aragona et al. (2015) showed a significant relationship between the psychotic characteristics of individuals and overeating. They used the SCL-90 questionnaire and found a significant association between obesity and psychoticism. The literature shows a different prevalence rate of psychoticism in patients with eating disorders (Seeman, 2014). Despite its prevalence rate, psychoticism can lead to worsening eating symptoms in these patients.

The results of our research also showed a significant relationship (34.3\%) between phobia and eating disorders $(\mathrm{P}<0.05)$. In a study of patients with anorexia nervosa, the results showed that they were afraid of becoming obese at any time during their illness (Rushford, 2006).
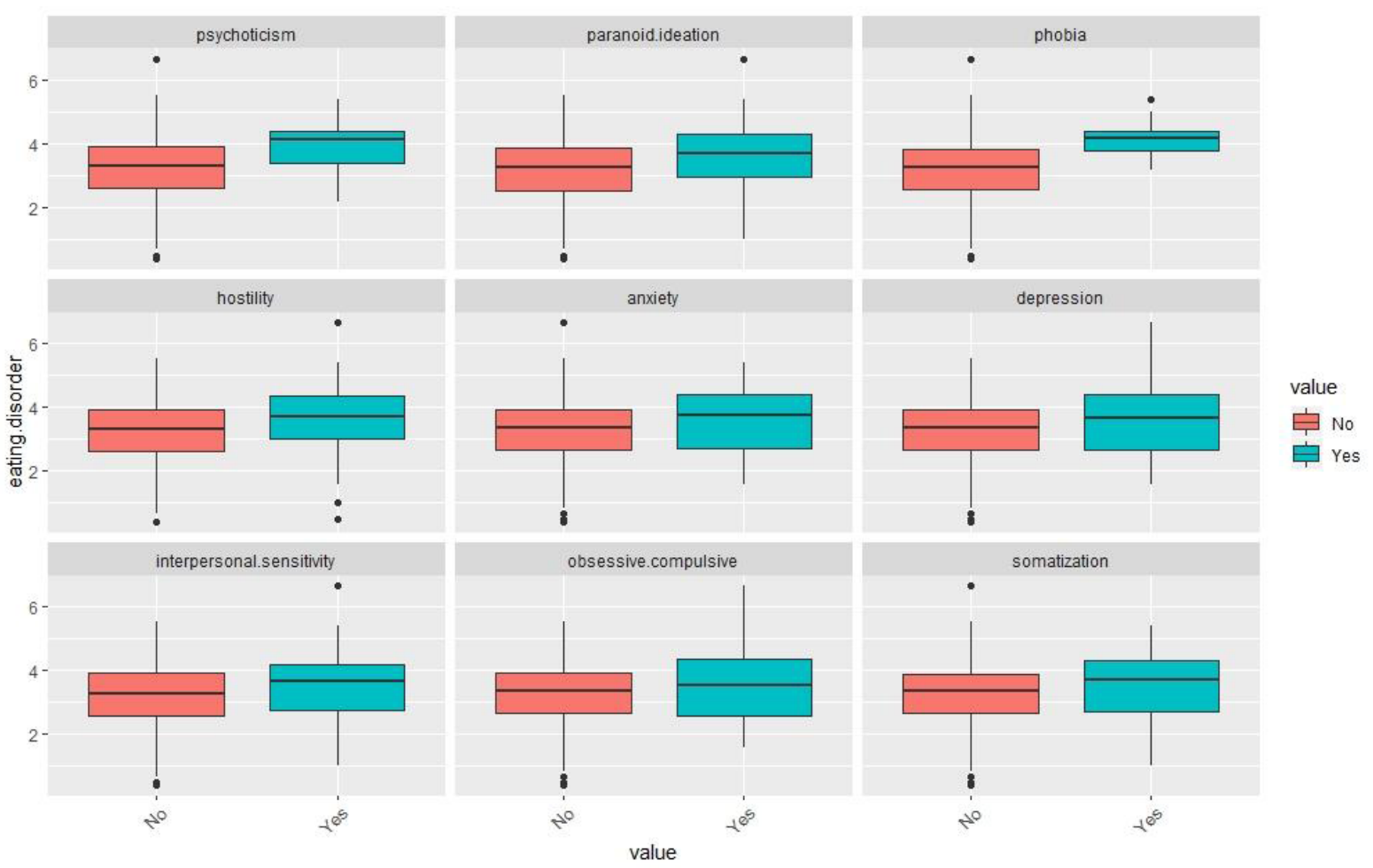

Figure 1. Relationship between total score of eating disorder symptoms andpsychological problems 
Table 3. Eating disorder symptoms and psychological problems in obese patient candidates for bariatric surgery

\begin{tabular}{|c|c|c|c|c|}
\hline \multicolumn{2}{|c|}{ SCL-90 Domains } & \multicolumn{2}{|c|}{ Eating Disorder Symptom, No.(\%) } & \multirow[t]{2}{*}{$\mathbf{P}^{*}$} \\
\hline & No & $100(95.2)$ & $23(65.7)$ & \\
\hline \multirow[t]{3}{*}{ Phobia } & Yes & $5(4.8)$ & $12(34.3)$ & $<0.001$ \\
\hline & Total & $105(100)$ & $35(100)$ & \\
\hline & No & $91(86.7)$ & $23(65.7)$ & \\
\hline \multirow[t]{3}{*}{ Anxiety } & Yes & 14(13.3) & $12(34.3)$ & 0.006 \\
\hline & Total & $105(100)$ & $35(100)$ & \\
\hline & No & $86(81.9)$ & $20(57.1)$ & \\
\hline \multirow[t]{3}{*}{ Depression } & Yes & 19(18.1) & $15(42.9)$ & 0.003 \\
\hline & Total & $105(100)$ & $35(100)$ & \\
\hline & No & $80(76.2)$ & $21(60.0)$ & \\
\hline \multirow{3}{*}{$\begin{array}{l}\text { Interpersonal sensitiv- } \\
\text { ity }\end{array}$} & Yes & $25(23.8)$ & $14(40.0)$ & 0.064 \\
\hline & Total & $105(100)$ & $35(100)$ & \\
\hline & No & $83(79.0)$ & $20(57.1)$ & \\
\hline \multirow[t]{3}{*}{ Obsessive compulsive } & Yes & $22(21.0)$ & $15(42.9)$ & 0.011 \\
\hline & Total & $105(100)$ & $35(100)$ & \\
\hline & No & $99(94.3)$ & $25(71.4)$ & \\
\hline \multirow[t]{3}{*}{ Psychoticism } & Yes & $6(5.7)$ & $10(28.6)$ & 0.001 \\
\hline & Total & $105(100)$ & $35(100)$ & \\
\hline & No & $85(81.0)$ & $21(60.0)$ & \\
\hline \multirow[t]{3}{*}{ Hostility } & Yes & 20(19.0) & $14(40.0)$ & 0.012 \\
\hline & Total & $105(100)$ & $35(100)$ & \\
\hline & No & $82(78.1)$ & $19(54.3)$ & \\
\hline \multirow[t]{3}{*}{ Paranoid Ideation } & Yes & $23(21.9)$ & $16(45.7)$ & 0.007 \\
\hline & Total & $105(100)$ & $35(100)$ & \\
\hline & No & $82(78.1)$ & $19(54.3)$ & \\
\hline \multirow[t]{2}{*}{ Somatization } & Yes & $23(21.9)$ & $16(45.7)$ & 0.007 \\
\hline & Total & $105(100)$ & $35(100)$ & \\
\hline
\end{tabular}

${ }^{*}$ P obtained from the Chi-square test. 
In a study by Keski-Rahkonen (2016), 17\% of people with eating disorders had a specific fear. However, the validity of the research does not confirm that eating disorders can have a significant relationship with phobia (Barry, Pietrzak, \& Petry, 2008). The evidence is largely inconsistent. These different results may be due to differences in the tools and methods used in the studies and the diversity between groups.

The present study found a significant relationship (34.3\%) between eating disorder symptoms and anxiety symptoms $(\mathrm{P}<0.05)$. Research has shown that anxiety is a common comorbid disorder associated with eating and weight disorders. Comorbid anxiety disorders in obesity have also been studied. Tyagi, H. reported that the adaptive prevalence of eating disorders in obsessive-compulsive disorder is associated with anxiety disorders (Bodenlos, Lemon, Schneider, August, \& Pagoto, 2011). In a study by Sidor, A. et al., the association between eating disorder symptoms and symptoms of depression and anxiety were similar in adolescent girls and boys, and there was a significant relationship between depression and anxiety with eating disorders (Moosavi \& Amini, 2017). Research on obese patients before bariatric surgery revealed that more than half of patients had anxiety disorders in the preoperative period, and the most common psychiatric diagnosis in these patients was anxiety disorders (Duarte-Guerra, Coêlho, Santo, Lotufo-Neto, \& Wang, 2017). We can say that anxious patients with eating disorders may use eating to reduce and soothe their stress.

The present study results also showed a significant relationship (40\%) between eating disorder symptoms and hostility $(\mathrm{P}<0.05)$. Hostility and aggressive behavior are relevant psychopathologic main traits in patients with an eating disorder. According to the results of a study, the severity of anger is a predictor for eating disorder episodes, which can be ameliorated by an individual's level of impulsivity. Patients with a high score on anger suppression are predisposed to self-traumatic behaviors. Patients with eating disorders may have insufficient anger expression in confronting anger and hopelessness. In addition, variant purging methods can be related to variant aspects of anger (Engel et al., 2007).

In this study, $40 \%$ of patients with eating disorder symptoms had interpersonal sensitivity, so this relationship was not statistically significant $(\mathrm{P}>0.05)$. Aldao et al. showed that interpersonal relationships are a risk factor associated with vulnerability to various psychological disorders, including anxiety, depression, and eating disorders (Aldao, Gee, De Los Reyes, \& Seager, 2016). The research extracted from a systematic review and experimental model (assessing the role of interpersonal functioning in maintaining a psychopathic eating disorder) showed that most of those with a psychopathic eating disorder had maladaptive personality traits and poor social relationships. People with restrictive behaviors such as anorexia do not express emotion in their relationships and stop expressing their feelings generally. These people prioritize others' feelings over their own (Arcelus, Haslam, Farrow, \& Meyer, 2013).

Atlas's study showed that interpersonal sensitivity was significantly correlated with dietary and lean expectations. Interpersonal sensitivity plays a potential role in people's dietary expectations and preventing eating disorders (Atlas, 2004). The results of these studies were not in line with the present findings, but there has not been extensive research on the relationship between eating disorders and interpersonal sensitivity. In a metaanalysis study using an empirical model, the response to interpersonal stress has been evaluated in patients with eating disorders. Although we used words such as social stress, social challenge, social stimuli, social duty, interpersonal stress, interpersonal sensitivity, rejection, negative evaluation, social rank, social exclusion, and social threat in combination with eating disorders, anorexia nervosa, and bulimia nervosa, no study on eating disorder and interpersonal sensitivity was found (Monteleone, Treasure, Kan, \& Cardi, 2018). As previously mentioned, there is limited research in this area, which may be due to cultural reasons; good appetite in some cultures is a sign of health and well-being, and decreased appetite is considered very worrying.

Finally, the current study results showed that $45.7 \%$ of patients with eating disorder symptoms had paranoid ideation symptoms. The results of several studies evaluating patients with eating disorders showed that they had interpersonal personality problems and decreased self-esteem. Women with eating disorders also exhibited more aggressive behaviors and had higher scores on subscales of the SCL-90-R checklist, including interpersonal sensitivity, paranoid ideation, psychosis, and obsession (Jones-Corneille et al., 2012). Fandiñoa et al. (2010) claimed that their study demonstrated the relationship between eating disorders and paranoid ideation and suggested a possible explanation for this relationship: patients become paranoid and pessimistic as they are observed by others eating frequently.

On the other hand, the study results have shown that paranoid personality disorder and paranoid perceptions are not significantly correlated with eating disorders, but the research results are contested by multiple studies 
(Petroni et al., 2007). In short, as obese people eat a lot of food and others see it, they become pessimistic about others who may judge them because of overeating, so paranoid thoughts may arise.

\section{Conclusion}

According to the results, the pre-surgical implementation of EDE-Q 6.0 and SCL-90-R in candidates for bariatric surgery can effectively recognize psychiatric and eating disorders among them. Because of the prevalence of these disorders in these patients, it is necessary to identify high-risk individuals before surgery to improve the effectiveness of the surgery. Furthermore, eating disorders in these patients is probably associated with a psychiatric disorder that should be considered. Thus, referring these patients to a psychologist or psychotherapist is a prerequisite for a successful bariatric surgery.

A limitation of this study is the low sample size. There were no other limitations. Since obese patients candidates for bariatric surgery are exposed to various psychiatric disorders, further studies are recommended to examine each psychiatric disorder, especially interpersonal sensitivity and paranoid perceptions in eating disorders.

\section{Ethical Considerations}

\section{Compliance with ethical guidelines}

The present article was approved by Iran University of Medical Sciences (Code: IR.IUMS.REC1396.31076).

\section{Funding}

This research was supported by the research project funded by the Research Deputy of Iran University of Medical Sciences.

\section{Authors' contributions}

All authors equally contributed to preparing this article.

\section{Conflict of interest}

The authors declared no conflict of interest.

\section{Acknowledgments}

The authors' deepest appreciation goes to the managers of Firoozgar Hospital, as well as nurses and patients who contributed to the study.

\section{References}

Aldao, A., Gee, D. G., De Los Reyes, A., \& Seager, I. (2016). Emotion regulation as a transdiagnostic factor in the development of internalizing and externalizing psychopathology: Current and future directions. Development and Psychopathology, 28(4pt1), 927-46. [DOI:10.1017/S0954579416000638] [PMID]

Aragona, M., Petta, A. M., \& Balbi, A. (2015). Psychotic phenomena in Binge Eating Disorder: An exploratory MMPI2 study. Archives of Psychiatry and Psychotherapy, 2, 13-20. [DOI:10.12740/APP/43321]

Arcelus, J., Haslam, M., Farrow, C., \& Meyer, C. (2013). The role of interpersonal functioning in the maintenance of eating psychopathology: A systematic review and testable model. Clinical Psychology Review, 33(1), 156-67. [DOI:10.1016/j. cpr.2012.10.009] [PMID]

Atlas, J. G. (2004). Interpersonal sensitivity, eating disorder symptoms, and eating/thinness expectancies. Current Psychology, 22(4), 368. [DOI:10.1007/s12144-004-1041-y]

Baceviciene, M., Balciuniene, V., \& Jankauskiene, R. (2020). Validation of the Lithuanian version of the Eating Disorder Examination Questionnaire 6.0 in a student sample. Brain and Behavior, 10(3), e01555. [DOI:10.1002/brb3.1555] [PMID] [PMCID]

Barry, D., Pietrzak, R. H., \& Petry, N. M. (2008). Gender differences in associations between body mass index and DSMIV mood and anxiety disorders: Results from the National Epidemiologic Survey on Alcohol and Related Conditions. Annals of Epidemiology, 18(6), 458-66. [DOI:10.1016/j.annepidem.2007.12.009] [PMID] [PMCID]

Bodenlos, J. S., Lemon, S. C., Schneider, K. L., August, M. A., \& Pagoto, S. L. (2011). Associations of mood and anxiety disorders with obesity: Comparisons by ethnicity. Journal of Psychosomatic Research, 71(5), 319-24. [DOI:10.1016/j.jpsychores.2011.03.004] [PMID]

Cella, S., Fei, L., D'Amico, R., Giardiello, C., Allaria, A., \& Cotrufo, P. (2019). Binge eating disorder and related features in bariatric surgery candidates. Open Medicine, 14(1), 407-15. [DOI:10.1515/med-2019-0043] [PMID] [PMCID]

da Luz, F. Q., Hay, P., Touyz, S., \& Sainsbury, A. (2018). Obesity with comorbid eating disorders: Associated health risks and treatment approaches. Nutrients, 10(7), 829. [DOI:10.3390/ nu10070829] [PMID] [PMCID]

Duarte-Guerra, L. S., Coêlho, B. M., Santo, M. A., Lotufo-Neto, F., \& Wang, Y, P. (2017). Morbidity persistence and comorbidity of mood, anxiety, and eating disorders among preoperative bariatric patients. Psychiatry Research, 257, 1-6. [DOI:10.1016/j.psychres.2017.07.020] [PMID]

Engel, S. G., Boseck, J. J., Crosby, R. D., Wonderlich, S. A., Mitchell, J. E., \& Smyth, J., et al. (2007). The relationship of momentary anger and impulsivity to bulimic behavior. Behaviour Research and Therapy, 45(3), 437-47. [DOI:10.1016/j. brat.2006.03.014] [PMID]

Fandiño, J., Moreira, R. O., Preissler, C., Gaya, C. W., Papelbaum, M., \& Coutinho, W. F., et al. (2010). Impact of binge eating disorder in the psychopathological profile of obese women. Comprehensive Psychiatry, 51(2), 110-4. [DOI:10.1016/j. comppsych.2009.03.011] [PMID]

Greenberg, I., Sogg, S., \& Perna, F. M. (2009). Behavioral and psychological care in weight loss surgery: Best practice update. Obesity, 17(5), 880-4. [DOI:10.1038/oby.2008.571] [PMID] 
Guisado, J. A., Vaz, F. J., López-Ibor, J. J., \& Rubio, M. A. (2001). Eating behavior in morbidly obese patients undergoing gastric surgery: Differences between obese people with and without psychiatric disorders. Obesity Surgery, 11(5), 576-80. [DOI:10.1381/09608920160556751] [PMID]

National Institute of Mental Health (NIMH). (2011). Eating Disorders. U.S: Department of Health and Human Services. https:/ / www.nimh.nih.gov/health/topics/eating-disorders

Jones-Corneille, L. R., Wadden, T. A., Sarwer, D. B., Faulconbridge, L. F., Fabricatore, A. N., \& Stack, R. M., et al. (2012). Axis I psychopathology in bariatric surgery candidates with and without binge eating disorder: Results of structured clinical interviews. Obesity Surgery, 22(3), 389-97. [DOI:10.1007/ s11695-010-0322-9] [PMID] [PMCID]

Keski-Rahkonen, A., \& Mustelin, L. (2016). Epidemiology of eating disorders in Europe: Prevalence, incidence, $\mathrm{CO}-$ morbidity, course, consequences, and risk factors. Current Opinion in Psychiatry, 29(6), 340-5. [DOI:10.1097/ YCO.0000000000000278] [PMID]

Lemstra, M. E., \& Rogers, M. R. (2016). Improving health-related quality of life through an evidence-based obesity reduction program: The healthy weights initiative. Journal of Multidisciplinary Healthcare, 9, 103-9. [DOI:10.2147/JMDH.S100693] [PMID] [PMCID]

Lykouras, L. (2008). Psychological profile of obese patients. Digestive Diseases, 26(1), 36-9. [DOI:10.1159/000109384] [PMID]

Mahmoodi, M., Moloodi, R., \& Ghaderi, A., Babai, Z., Saleh, Z., \& Alasti, H., et al. (2016). The Persian version of eating disorder examination questionnaire and clinical impairment assessment: Norms and psychometric properties for undergraduate women. Iranian Journal of Psychiatry, 11(2), 67-74. [PMID] [PMCID]

Matini, D., Jolfaei, A. G., Pazouki, A., Pishgahroudsari, M., \& Ehtesham, M. (2014). The comparison of severity and prevalence of major depressive disorder, general anxiety disorder and eating disorders before and after bariatric surgery. Medical Journal of the Islamic Republic of Iran, 28, 109. [PMID][PMCID]

Mitchell, J. E., Selzer, F., Kalarchian, M. A., Devlin, M. J., Strain, G. W., \& Elder, K. A., et al. (2012). Psychopathology before surgery in the longitudinal assessment of bariatric surgery-3 (LABS-3) psychosocial study. Surgery for Obesity and Related Diseases, 8(5), 533-41. [DOI:10.1016/j.soard.2012.07.001] [PMID] [PMCID]

Mohammadzadeh, A., \& Vahedi, M. (2016). [The correlation between obsessive compulsive features and dimensions of pathological eating attitudes in non-clinical samples (Persian)]. Qom University of Medical Sciences Journal, 10(10), 41-9. http://journal.muq.ac.ir/article-1-1385-en.html

Monteleone, A. M., Treasure, J., Kan, C., \& Cardi, V. (2018). Reactivity to interpersonal stress in patients with eating disorders: A systematic review and meta-analysis of studies using an experimental paradigm. Neuroscience \& Biobehavioral Reviews, 87, 133-50. [DOI:10.1016/j.neubiorev.2018.02.002] [PMID]

Moosavi, S. M., \& Amini, F. (2017). Role of anxiety, depression and anger in eating disorders-structural model. American Journal of Psychiatry and Neuroscience, 5(4), 40-4. [DOI:10.11648/j. ajpn.20170504.11]

Papelbaum, M., Moreira R. O., do Nascimento Gaya, C. W., Preissler, C., \& Coutinho, W. F. (2010). Impact of body mass index on the psychopathological profile of obese women Brazilian Journal of Psychiatry, 32(1), 42-6. [DOI:10.1590/S151644462010000100009] [PMID]

Petroni, M. L., Villanova, N., Avagnina, S., Fusco, M. A., Fatati, G., \& Compare, A., et al. (2007). Psychological distress in morbid obesity in relation to weight history. Obesity Surgery, 17(3), 391-9. [DOI:10.1007/s11695-007-9069-3] [PMID]

Pourghassem Gargari, B., Hamed Behzad, M., Seyed Hejazi, N., Kooshavar, D., \& Karami, S. (2010). [Relation of body mass index to eating attitude in Tabrizian high school girls (Persian)]. Medical Journal of Tabriz University of Medical Sciences, 32(3), 24-9. https://mj.tbzmed.ac.ir/fa/Article/6779

Rahmani, A., Sayehmiri, K., Asadollahi, K., Sarokhani, D., Islami, F., \& Sarokhani, M. (2015). Investigation of the Prevalence of Obesity in Iran: A Systematic Review and Meta-Analysis Study. Acta Medica Iranica, 53(10), 596-607. [PMID]

Ransom, D., Ashton, K., Windover, A., 7 Heinberg, L. (2010) Internal consistency and validity assessment of SCL-90-R for bariatric surgery candidates. Surgery for Obesity and Related Diseases, 6(6), 622-7. [DOI:10.1016/j.soard.2010.02.039] [PMID]

Rushford, N. (2006). Fear of gaining weight: Its validity as a visual analogue scale in anorexia nervosa. European Eating Disorders Review: The Professional Journal of the Eating Disorders Association, 14(2), 104-10. [DOI:10.1002/erv.682]

Saleem, M., Sattar, S., Zafar, M., \& Bin Ismail, R. (2014). Link between eating disorders and depression. Pakistan Journal of Commerce and Social Sciences, 8(3), 925-37. https://www. econstor.eu/handle/10419/188178

Saunders, R., Johnson, L., \& Teschner, J. (1998). Prevalence of eating disorders among bariatric surgery patients. Eating Disorders, 6(4), 309-17. [DOI:10.1080/10640269808249267]

Scott, K. M., McGee, M. A., Wells, J. E., \& Browne, M. A. O. (2008). Obesity and mental disorders in the adult general population. Journal of Psychosomatic Research, 64(1), 97-105. [DOI:10.1016/j.jpsychores.2007.09.006] [PMID]

Seeman, M. V. (2014). Eating disorders and psychosis: Seven hypotheses. World Journal of Psychiatry, 4(4), 112-9. [DOI:10.5498/ wjp.v4.i4.112] [PMID] [PMCID]

Torres, S., Guerra, M. P., Lencastre, L., Vieira, F., Roma-Torres, A., \& Brandão, I. (2011). Prevalence of alexithymia in anorexia nervosa and its association with clinical and sociodemographic variables. Jornal Brasileiro de Psiquiatria, 60(3), 182-9. [DOI:10.1590/S0047-20852011000300006]

Tyagi, H., Patel, R., Rughooputh, F., Abrahams, H., Watson, A. J., \& Drummond, L. (2015). Comparative prevalence of eating disorders in obsessive-compulsive disorder and other anxiety disorders. Psychiatry Journal, 2015, 186927. [DOI:10.1155/2015/186927] [PMID] [PMCID]

van Hout, G. C. M., Boekestein, P., Fortuin, F. A. M., Pelle, A. J. M., \& van Heck, G. L. (2006). Psychosocial functioning following bariatric surgery. Obesity Surgery, 16(6), 787-94. [DOI:10.13 81/096089206777346808] [PMID]

World Health Organization (WHO). (2021). Obesity and overweight. Retrieved from: https://www.who.int/news-room/ fact-sheets/detail/obesity-and-overweight 